Essay

\title{
Inclusive Education as a Democratic Challenge-Ambivalences of Communities in Contexts of Power
}

\author{
Meike Kricke * and Stefan Neubert \\ Faculty of Human Sciences, University of Cologne, Cologne 50931, Germany; s.neubert@uni-koeln.de \\ * Correspondence: meike.kricke@uni-koeln.de
}

Academic Editors: Paul Standish and SunInn Yun

Received: 20 September 2016; Accepted: 3 January 2017; Published: 10 January 2017

\begin{abstract}
Our essay is keyed to the second and fourth chapter of Dewey's Democracy and Education. We start by looking at education as a social function and close with education as growth. References will be made to other writings of Dewey's, especially from the later works. We connect Dewey's classical approach with inclusion as a feature of contemporary debates in educational theory and practice. Within this frame, we also draw critical connections to selected perspectives from Michel Foucault and Zygmunt Bauman. The aim is twofold: First, we wish to show the lasting relevance of Dewey's approach in and for our time. Second, we intend to invite some perspectives for reconstructing the Deweyan tradition in accordance with more recent developments and challenges, including the ambivalences of communities in modernity, especially in times of liquid modernity as described by Bauman.
\end{abstract}

Keywords: inclusion; democracy; education; Dewey; Bauman; Foucault; communities; power; technologies in culture

\section{Introduction}

In this essay, we connect Dewey's classical approach to democracy and education with "inclusion" as an element of contemporary debates in educational theory and practice. We start with his discussion of "education as a social function" and close with his idea of "education as rowth". Within this frame, we draw critical connections to selected perspectives from Zygmunt Bauman and Michel Foucault. (For a more detailed discussion of affinities and differences between the approaches of Dewey, Bauman and Foucault (as well as constructive and productive ways of interconnecting their perspectives), see Garrison/Neubert/Reich $(2012,2016)[1,2]$. The aim is twofold: First, we wish to show the lasting relevance of Dewey's approach in and for our time. Second, we intend to invite some perspectives for reconstructing the Deweyan tradition in accordance with more recent developments and challenges, including the ambivalences of communities in modernity, especially in times of liquid modernity as described by Bauman.

\section{Education as a Social Function}

In the first and the second chapter of Democracy and Education, Dewey discusses education as a necessity of life and as a function of society. Education is inevitable in human life, because humans are cultural beings. In a Darwinian perspective, Dewey argues that life persists through processes of transmission. This includes a biological dimension and-especially in the case of human beings-a social and cultural dimension. Dewey identifies the latter as transmission through communication:

"Society not only continues to exist by transmission, by communication, but it may fairly be said to exist in transmission, in communication. There is more than a verbal tie between 
the words common, community, and communication. Men live in a community in virtue of the things which they have in common and communication is the way in which they come to process things in common." [3] (MW 9: 7)

He observes among the things that need to be shared in common are "aims, beliefs, aspirations, knowledge" which constitute "a common understanding" or "like-mindedness" (MW 9: 7). It is crucial that these things cannot be exchanged externally like material objects that are passed from one to another. Instead, transmission must be based on the participation in conjoint activities wherein each individual shares in the co-construction and exchange of meanings. This is why Dewey introduces, in the first chapter of Democracy and Education, the concept of "communication" as a fundamental component of education and educational theory. In the history of philosophy of education, he was a trailblazer who first anticipated the fundamental place that "communication" would occupy as a matter of commonsense in 20th- and 21st-century educational theories. He observes: "Not only is social life identical with communication, but all communication ... is educative." (MW 9: 8)

Dewey was also one of the first philosophers of education who systematically included the modern term "environment" into educational theory. In the second chapter of Democracy and Education he insists: "We never educate directly, but indirectly by means of the environment" (MW 9: 23). He notes that the term "environment" means "something more than surroundings which encompass an individual" (MW 9: 15). This distinction is crucial because it indicates Dewey's fundamentally interactive understanding of education and learning. He argues that the "environment consists of the sum total of conditions which are concerned in the execution of the activity characteristic of a living being" (MW 9: 26). An important part of educative environments consists of the persons with which an individual interacts through ways of communication and participation. Dewey observes that the social environment "consists of all the activities of fellow beings that are bound up in the carrying on of the activities of any one of its members. It is truly educative in its effect in the degree in which an individual shares or participates in some conjoint activity" (MW 9: 26). This is true for all educative processes in society, starting with the more informal ways of learning through direct partaking in the activities of social groups, communities, and institutions in the contexts of daily living. Dewey insists that the more formal ways of learning, say in institutions like schools, should always be continuous with the comprehensive informal contexts. The institution of the formal sector in education is itself a function of social developments:

"As a society becomes more complex, however, it is found necessary to provide a special social environment which shall especially look after nurturing the capacities of the immature. Three of the more important functions of this special environment are: simplifying and ordering the factors of the disposition it is wished to develop; purifying and idealizing the existing social customs; creating a wider and better balanced environment than that by which the young would be likely, if left to themselves, to be influenced." (MW 9: 26-27)

\section{The Necessity of Communities for Democracy and Education}

In The Public and Its Problems, Dewey observes: "Democracy must begin at home, and its home is the neighborly community." (LW 2: 368) Some pages later he continues:

"In a word, that expansion and reinforcement of personal understanding and judgment by the cumulative and transmitted intellectual wealth of the community which may render nugatory the indictment of democracy drawn on the basis of the ignorance, bias and levity of the masses, can be fulfilled only in the relations of personal intercourse in the local community ... Vision is a spectator; hearing is a participator ... We lie, as Emerson said, in the lap of an immense intelligence. But that intelligence is dormant and its communications are broken, inarticulate and faint until it possesses the local community as its medium." (LW 2: 371f.) 
The passage was written in the mid-1920s when Dewey defended his vision of participatory and pluralistic democracy and reflected on the risks and challenges of democratic publics under the modern conditions of a "Great Society". He observed that practices of capitalism increasingly tended to put democracy at risk. In the early 1930s, he claimed in a radio lecture, "American Education Past and Future," that in earlier times "the aims of political democracy were easily understood, since they were in harmony with the conditions of soil and occupation. Now there are vast and concentrated aggregations of wealth; there are monopolies of power; great unemployment; a shutting down of doors of opportunity, a gulf between rich and poor, and no frontier to which the hard put can migrate." (LW 6: 95-96)

There are considerable historical differences in the development of capitalism and its relations to democracy between Northern America and Europe. These differences have contributed to somewhat different democratic traditions. The movements toward democracy have been more troublesome and continually threatened by set-backs and or even temporal defeats in Europe than in the United States. Dewey observes that democracy as a moral ideal combines "two ideas which have historically often worked antagonistically: liberation of individuals on one hand and promotion of a common good on the other" (LW 7: 349). In Europe, especially the "promotion of a common good" was more contested than in America. Capitalist production with all its contradictory aspects including economic exploitation and emancipation struggles for social and democratic rights has had a more contested and uneven development. In this connection, the "promotion of the common good" has always been divided into separate camps of interest competing for political influence. Therefore, there was a relatively strong emphasis on the resolution of conflicts through mechanisms of representative democracy. On the other hand, traditions of direct democratic participation seem to be weaker, upon the whole, than in America.

Against this background, Dewey's insistence that the prosperity of local communities is necessary for the prosperity of democracy at large still poses a challenge, today. Local communities in the Deweyan democratic sense stand for direct participation in interactions that allow for face-to-face acquaintance. They are communities of learning, of developing joint interests and cooperatively solving common problems. They offer opportunities for direct democratic engagement in groups, networks, and social movements. They articulate the multitude of experiences by which democracy in enlivened. They are a backbone of civil society because they render democracy a lived experience that of itself shows its advantages as a way of life for all who participate. Therefore, the orientation toward the bottom expressed in the idea of local and immediate communities is important for democracy and education today no less than it was in Dewey's age. (In Germany, a still important background of this necessity also lies in the disastrous misuse of the word "community" in the times of National Socialism that has for many decades led (as a reaction) to a widespread public and political underestimation of the democratic and educational values of communities - at least in former Western Germany).

Direct democracy is, of course, not opposed to representational democracy. It is "because I believe in democracy that I believe in this principle of just representation," says Dewey, "especially when it is backed up by proportional representation that gives the minority its full voice." (LW 9: 318) He is not willing to identify democracy with sheer majority rule. It is equally important to recognize and secure minority rights. "Majority rule, just as majority rule, is as foolish as its critics charge it with being." (LW 2: 365) Dewey points to the importance of the processes and means by which a majority is attained. They must include the involvement and active participation of minority voices and perspectives in deliberation, negotiation, formation of public opinion, and decision making:

"[A]ntecedent debates, modification of views to meet the opinions of minorities, the relative satisfaction given the latter by the fact that it has had a chance and that next time it may be successful in becoming a majority ... It is true that all valuable as well as new ideas begin with minorities, perhaps a minority of one. The important consideration is that opportunity be given that idea to spread and to become the possession of the multitude." (LW 2: 265) 
Dewey's understanding of just representation is deeply connected with his insights into the uniqueness of each individual and the resourcefulness of each cultural group or community. It is also linked with his insistence on the democratic challenge to recognize and appreciate differences as a means for enriching one's own life experience (see LW 14: 228). This implies respect for others whose beliefs and convictions we consider wrong. The "mechanics of democracy can function only when there is a clear understanding of the community of interest that the membership has, and likewise a deep, sympathetic understanding of one another's weaknesses, shortcomings, and proneness to error" (LW 9: 344). For Dewey, these and similar principles are necessary conditions for the emergence and articulation of a social intelligence that will be of decisive import for the success or failure of democratic living together: "The problem of bringing about an effective socialization of intelligence is probably the greatest problem of democracy today." (LW 7: 365-366) With Dewey we believe this is, among other things, a fundamental challenge for education-the problem of providing sufficient opportunities for all learners to develop social intelligence and to make constructive use of their democratic rights for learning.

It is our intention in this essay to take a look at two main aspects in this connection from a perspective of today: On the one hand, we will suggest that a Deweyan understanding of the social function of education must today encompass recent debates on inclusion as a social and educational challenge. We believe that Dewey's idea of democracy based on principles of diversity and participation gives a philosophical foundation for establishing and sustaining inclusive environments in education and social life today. The idea behind the title of our essay is that in contemporary contexts, education must be inclusive if it is to do justice to the Deweyan sense of democracy. On the other hand, regarding the idea of community contained in Dewey's concept of social environments, we will suggest that the Deweyan tradition is still relevant. However, our claim is that it is possible and helpful today to complement Dewey's approach with more recent perspectives on the ambivalences and potentially dark sides of community formation in our own time. To do so, we will turn to Zygmunt Bauman's analyses of life in liquid modernity. We will use Michel Foucault's account of technologies in culture as a theoretical tool for reflecting on the role of communities in democracy and education and connecting the perspectives of Dewey and Bauman.

\section{Inclusion and Inclusive Education}

The United Nations' Convention on the Rights of Persons with Disabilities, passed in 2006 and ratified by Germany in 2009, has helped to intensify debates on inclusive education which had started relatively late in Germany. In the international discussions about inclusion, there have been several approaches to defining the concept, ranging from narrower to broader and more generous ways of understanding. For example, one conceptualization that is largely prevalent in Germany until the present day is the identification of the idea of inclusion with the integration of persons with disabilities into the regular school system and other areas of social life. Compared to international standards (see: UNESCO Guidelines 2005 [4]), this definition is relatively narrow. Many broader definitions have been influenced by the Statement of Policy of the Toronto District School Board (2011) which served as an orientation for other groups, institutions, and countries for creating their own inclusive principles. The Toronto Statement claims that a comprehensive understanding of inclusion must at least comprise the following five standards of participation and anti-discrimination:

(1) Ethno-Cultural Equity and Anti-Racism;

(2) Gender Equity and Anti-Sexism;

(3) Diversity in Sexual Orientations and Anti-Homophobia;

(4) Socio-Economic Equity and Anti-Classism;

(5) Equity for Persons with Disability. (For an extensive interpretation of these five standards from a Deweyan perspective of democracy and education see Garrison/Neubert/Reich (2016) [2], especially chapter 9 . The authors also provide a critical discussion of perspectives and 
shortcomings in Dewey on issues of social class, race, and gender. For Dewey and classism see also Westbrook (1991) [5]; for Dewey and racism see Eldridge (2012) [6], Neubert (2012) [7]; for Dewey and feminism see Seigfried (2002) [8].

Such a broad and comprehensive understanding of inclusive education often prevails in international contexts and debates. For example, the UNESCO Guidelines for Inclusion (2005) [4] (p. 10) define the term as follows: "Inclusion, thus, involves adopting a broad vision of Education for All by addressing the spectrum of needs of all learners, including those who are vulnerable to marginalisation and exclusion."

Reich comments on these standards with a view on the developments in Germany (the authors' country):

"Inclusion is more comprehensive than what was formerly attempted by programs of integration. It is a broad societal claim implying that society as a whole has to take active measures that are appropriate for reducing all sorts of discrimination of individuals and groups on all levels. The aim is to provide for equity of chances for development of all members of society as far as possible." (Reich (2012) [9] (p. 39); transl. ours, M.K./S.N. [9])

Following Booth and Ainscow (2011) [10] (p. 9), inclusive education "is about increasing participation for all children and adults. It is about supporting schools to become more responsive to the diversity of children's backgrounds, interests, experience, knowledge and skills". Like other institutions, organizations, and agencies in society, schools are called upon to appreciate the diverse backgrounds and conditions, interests and experiences, as well as the knowledge and the capacities of all participants in responsible ways that support their chances for growth.

In their Index for Inclusion, Booth and Ainscow further specify ways how schools in different contexts can implement inclusive ideas as a bottom-up process with consequences on all levels of school-life in interaction with the social context. They claim:

"Inclusion in the Index, then, is a principled approach to the development of education and society. It is linked to democratic participation within and beyond education. It is not about an aspect of education to do with a particular group of children. It is concerned with bringing coherence to the development activities that take place under a variety of headings so that they encourage the learning and participation of everyone: children and their families, staff and governors and other community members. ... Increasing inclusion involves reducing exclusion. It involves combating the exclusionary pressures that impede participation." (Booth and Ainscow (2011) [10] (p. 20))

On the level of the classroom, principles of inclusive teaching and learning include, among other things, competencies including "open-mindedness, self-awareness and reflection, and a commitment to social justice" (Garmon in: Blecker and Boakes (2010) [11] (p. 436)) on the part of all teachers and educators. They also imply relational approaches to pedagogy (see Reich (2014) [12]) that strongly emphasize processes of communication and meta-communication, multi-perspectival experiences and multimodal practices, as well as the appreciation of diversity and active participation of all.

\section{Ambivalences of Communities in Liquid Modernity}

Bauman observes that a continuing trait of modern society lies in dissolving traditional structures combined with the understanding that the production of order in social life is an intentional and deliberate human task (see Bauman (2000) [13] (p. 4)). He distinguishes between "solid" and "liquid modernity". "Solid modernity" refers to the relatively heavy structures of social order in past times as exemplified, among other things, by the early 20th-century Fordist factory. Bureaucracy, panoptism, and big brother are other regular elements of the solid version of modernity, while the concentration camp stands for its most extreme and murderous manifestations (see Bauman (2000) [13] 
(pp. 25f.)). By contrast, the term "liquid modernity" responds to the increasingly flexible, dynamic, light, network-like, and liquefied social conditions of our times (Bauman (2000) [13] (pp. 25f.)). It is characteristic for liquid modernity that crucial parameters of modern life have changed despite the underlying continuities between the solid and the liquid state.

We believe that education in many contemporary societies is captured somewhere between the solid and liquid stages. There seems to be a paradox in educational theory and practice. On the one hand, we find relatively solid institutional frameworks like tight educational bureaucracies and hierarchies, the closed and quadrangular classroom, the uniform rhythm of time management and disciplinary structure of contents, the uniform use of materials, textbooks and methods, standardized measurement and grading, and studying for examinations. They represent the still-extant and often dominating attitude of "one sizes fits all" in local as well as global educational contexts. On the other hand, we encounter a social world characterized by diversity, flexibility, and individual responses to life conditions in liquid society. The solid structures in education often seem to restrict the abilities of learners to respond to more liquid life conditions. The situation calls for a critical and constructive response in the sense of new ways of learning-ways that in allusion to Bauman we may call "liquid learning". We will argue in this essay not only that inclusion is a necessary component in this connection, but that this component must be built on a critical reflection and understanding of the ambivalences of communities-as the necessary social contexts of communication and learning -in liquid times. "Liquid learning" claims that the challenge for education consists in addressing the tension between solid structures and the rights and claims of all individuals to participate constructively in the organization of learning and the shaping of learning communities and environments which correspond to the liquid conditions of life.

In his account of Liquid Modernity, Bauman provides a critical picture of the role of communities in contemporary society. He highlights many cases of community formation that represent asymmetrical relations of power and tend to exclude in order to establish an apparently stable "we". Bauman always points to the ambivalences that are deeply embedded in such community constructions. First of all, it is a deep-seated paradox of recent forms of communitarianism that all such communities in liquid modernity are postulated, they are "projects rather than realities, something that comes after, not before the individual choice. The community 'as seen in communitarian paintings' would be tangible enough to be invisible and to afford silence; but then communitarians won't paint its likenesses, let alone exhibit them." (Bauman (2000) [13] (p. 169)) Such communities are constructed rather than given. They are experienced in imagination rather than grounded in the solid structures of social living. In the face of "the new fragility of human bonds" (Bauman (2000) [13] (p. 170)), they appeal to the desire for stable and secure forms of identity. To provide supposed security of belonging and unambiguous orientations, they need to purge ambivalence and complexity, the very traits that characterize liquid modernity throughout. They appeal to their members as solid islands in the flux of living. Therefore, they often tend to be closed and homogeneous. They pretend to offer security through essentialized visions of community, identity, and belonging: "The community of the communitarian gospel is a home writ large (the family home, not a found home or a made home, but a home into which one is born, so that one could not trace one's origin, one's 'reason to exist', in any other place)" (Bauman (2000) [13] (p. 171)). They draw clear lines of distinction and separation between members and strangers, those who are included and those who are excluded. Among the examples Bauman mentions are (renascent forms of) nationalism and patriotism (see Bauman (2000) [13] (pp. 172-176)), but he also points to the gated communities of the rich and ethnic ghettos of the poor to indicate contemporary trends of separation, purification, and exclusion (see Bauman (2000) [13] (p. 180)).

From a Deweyan perspective, we may interpret these developments as examples for a "compartmentalization" of social life (see LW 10: 26-27) that threatens democratic living together in liquid modernity. Bauman, too, suggests that such rigorous and exclusive forms of community formation readily become dangers for civil society. He claims that there is only one way of constituting and sustaining communities today that counter these exclusive tendencies. In contrast to the 
"communitarian gospel" (e.g., Bauman (2000) [13] (p. 171)), he proposes "the republican model of unity" as an alternative democratic form of association. He understands this model as "an emergent unity which is a joint achievement of the agents engaged in self-identification pursuits, a unity which is an outcome, not an a priori given condition, of shared life, a unity put together through negotiation and reconciliation, not the denial, stifling or smothering out of differences." (Bauman (2000) [13] (p. 178)) This is very close to Dewey's understanding of democratic communities, focused on interactive problem-solving, that build on diversity and participation, regard unity as an accomplishment, and seek solutions as social co-constructions to be deconstructed and re-constructed in new situations. Dewey believes that the appreciation of diversity and the inclusion of differences is a fundamental component of the democratic attitude to life: "To cooperate by giving differences a chance to show themselves because of the belief that the expression of difference is not only a right of the other persons but is a means of enriching one's own life-experience, is inherent in the democratic personal way of life" (LW 14: 228). Despite this affinity between Bauman and Dewey—of which Bauman himself seems to be unaware-we think that a critical combination of the perspectives of both may help us to reconsider the Deweyan project in and for our time. Bauman's emphasis on the ambivalent and even dark sides of communities poses a challenge with regard to the elaboration of a reflective and critical understanding of inclusion that does justice to the comprehensive claims of democracy and education today. We suggest that a brief detour to Michel Foucault and his systematic account of technologies in culture can be helpful to perform this task of reflection and criticism.

\section{Challenges for Inclusive Education: A Critical Reflection through Foucault's Theory of Technologies}

In his reflections on the technologies of the self, Foucault (1988) [14] discusses the opportunities, chances, and risks of subjects acting in contexts of power relations. He gives a broad account of the role of technologies in cultural history and especially modern societies (see Garrison/ Neubert/Reich (2016) [2] (pp. 133-149)). For Foucault, we can distinguish at least four dimensions of technology: (1) technologies of production; (2) technologies of sign systems; (3) technologies of power and domination; and (4) technologies of the self (see Foucault (1988) [14] (p. 18)). These four levels can be distinguished analytically but never separated because they interpenetrate each other deeply in all cultural contexts. We think that this approach offers a good meta-perspective for reflecting on conclusions regarding the ambivalences of communities for inclusive education today.

If we regard recent debates on inclusion and inclusive education, we often hear the claim that inclusion, in the first place, is a question of "attitudes" and "beliefs" (or in German, "Haltung"). This statement is true in the sense that inclusion cannot be realized without the intentional, deliberate, and reflective sharing of subjects in dialogue with others. Teachers and learners have to position themselves towards the fundamental values and claims of inclusion in their direct and immediate practices within their learning communities. For example, the World Health Organization points out that " $[\mathrm{t}]$ he principles of inclusion should be built into teacher training programs, which should be about attitudes and values not just knowledge and skills." (WHO (2011) [15] (p. 222)) In alignment with Foucault, we may say that this focus on attitudes applies to the level of technologies of the self. (For a recent discussion of inclusion and inclusive education from a Foucauldian perspective, see, among others, Peters and Besley (2014) [16]. They discuss processes of social exclusion/inclusion in connection with Foucault's analyses, from the 1960s and 1970s, of the modern history of power and social exclusion. We here use a somewhat different and more comprehensive approach by focusing on Foucault's later theory of technologies in culture, elaborated in the early 1980s, which includes the technologies of power relations and considers them in their complex interrelations with the other forms of technologies, with a strong emphasis on the technologies of the self and the hermeneutics of the subject.) In this context, the emphasis on the role of individual as well as shared attitudes and beliefs is highly plausible under the perspective of an educational approach that takes democratic claims to participation seriously. It suggests that these attitudes and beliefs have to be constructed by individuals in dialogue with others, i.e., discussed and negotiated in educational communities. 
However, Foucault's meta-perspective reminds us that the focus only on attitudes and beliefs is myopic and easily becomes naïve unless the other technological dimensions are sufficiently taken into account. The more comprehensive picture that we suggest in accordance with Foucault must at least include the following considerations:

(1) Technologies of production constitute the material foundation of all other technologies in culture. On this level, each society needs to create and sustain practices of production that provide things, resources, goods, and values which cannot only be consumed and exchanged, but also used as means and instruments for producing other things, resources, goods, and values. These technologies represent the necessary basis without which no society can sustain and develop its conditions of life and forms of organization. They produce economic wealth and constitute necessary conditions for the emergence of cultural practices and the collective life of subjects in cultures. However, they do not completely determine the ways and results of these interactions. If we apply this perspective to questions of inclusion and education today, we must observe that educators cannot just ignore market conditions under which the technologies of production are organized in capitalist societies. There is a tension between capitalism, on the one hand, and democracy and education on the other. The market represents standardization, while democracy and education stand for the appreciation of unique individuals and experiences in all their diverse contexts and potentials. This includes differences like gender, social status, cultural backgrounds, sexual orientation, ages, disabilities, and many more. In connection with this fundamental tension, the market represents equality of access under conditions of "survival of the fittest," while democracy and education stand for individual and social growth of all through principles of participation that include resources of all members in the multitude of talents.

Against this background, an intelligent approach to inclusion must support learners in becoming effective agents, competent participants, well-informed and critical observers who live emancipated lives in a market society under liquid modern conditions. This includes conceiving of education as a form of resistance against capitalist pressures towards "one size fits all" and "survival of the fittest" approaches with their attendant reductionisms. This is especially important in the face of the growing economization of education that we currently observe on a global scale (see Garrison/Neubert/Reich (2016) [2]). We here encounter an especially important challenge regarding communities in education. The ambivalences, diagnosed by Bauman, fully apply if we think of the growing tendency worldwide to organize education according to the principles of gated communities. In many countries, the private school sector as well as the number of private universities is growing strongly. In countries like Argentina, Brazil, and also Sweden, the number of private schools is increasing, and in many parts of the world, higher education today requires immense university fees, like in the United States or England (see Stiglitz (2015) [17]). It often seems that the communities of the rich seize more and more educational resources at the expense of the democratic participation of all. The gated forms of community life that also appear in urban segregation, processes of gentrification, ethnic ghettoization, etc. constitute new forms of social "compartmentalization" that tend to block intercommunication between largely isolated areas of daily life. These considerations suggest that educators unavoidably participate in the technologies of production, whether they know it or not, whether they like it or not, whether they reflect on it critically or just take it for granted. Against the background of what Joseph Stiglitz describes as "The Great Divide" between rich and poor, the "haves" and "have-nots" that appears and has important consequences on almost all levels of society including economics, politics, culture, justice, as well as education (see Stiglitz (2015) [17]), we believe that the risk should not be underestimated that well-funded education and schooling increasingly become a game of the relatively rich, realized in schools with abundant and diverse resources, to the disadvantage of inclusive education for all. Democracy and education in a Deweyan sense must counteract this risk. In his forceful criticism of the economic order of his time, Dewey already observed the mentioned tension between capitalism and democracy and education as well as the attendant dangers of compartmentalization. What his criticisms claimed under solid modern conditions, we must exact today for liquid modernity. 
(2) Technologies of sign systems create and sustain "signs, meanings, symbols, or signification" (Foucault (1988) [14] (p. 18)) that permit cultural practices. They are essential for organizing these practices into symbolic systems and representing them in structures like texts and discourses. They constitute the symbolic fundament for all other technologies in culture. They are the basic forms of meaning making without which representation and articulation would be impossible. Stuart Hall defines discourse in the Foucauldian sense as "a group of statements which provide a language for talking about ... a particular kind of knowledge about a topic. When statements about a topic are made within a particular discourse, the discourse makes it possible to construct the topic in a certain way. It also limits the other ways in which the topic can be constructed." (Hall (1992) [18] (p. 291)) What is more, Foucault and other poststructuralists have shown that no system of representation can ever be complete and stable. This is because meaning-making processes are always dynamic, ambiguous, and open-ended. In the Cologne program of interactive constructivism (see Reich (2009) [19]; Garrison/Neubert/Reich (2012) [1]; 2016 [2]), we say that systems of representation are cultural constructions that can be deconstructed and reconstructed in many ways. We may use the Foucauldian term "discursive formations" to explain two fundamental challenges such systems can imply for our focus, in this essay, on questions of inclusive education and ambivalences of communities today. "Discursive formations" are constellations of meaning making and knowledge production that include more than a single discourse, but rather a combination of many distinct discourses that work together in a given time and cultural context and mutually influence and reinforce each other. Discursive formations as well as the discourses that constitute them are always complex, flexible, dynamic, and multifunctional.

First, against this background of what has been said in the foregoing parts of our essay, we should consider the ways in which influential contemporary mainstreams in educational thought-i.e., powerful discursive formations-contextualize and influence debates about inclusive education in theory and practice as well as the educational communities in which these debates are going on. We believe that one very strong global formation today circles around the idea of "human capital" and the attendant economization of education. Among the characteristics of this discursive formation is a generalized will to measurement that suggests that everything relevant in education is measureable. We see one expression of this will in the almost omnipresent influence of studies like the Programme for International Student Assessment (PISA) on debates about education in the general public as well as among educational policy makers, administrators, researchers, as well as teachers and parents. This is not to devalue programs like PISA insofar as these programs are instruments for measuring important data on education in an internationally comparative perspective. The problem arises, to our minds, when there is a tendency to reduce educational debates to the comparative success and ranking of systems with a narrow view on standardized and measureable performances. We believe that this tendency which can be observed in almost all educational systems around the globe seriously puts the inclusive project at risk Inclusion, generously understood, must insist on the uniqueness of individuals that cannot be reduced to numbers, the diversity of learners that cannot be narrowed down through scales of standardized measurement, the participation of all in processes of development through communication and negotiation that cannot be boiled down to one size fits all thinking. The challenge for educational communities consists of counteracting such reductionist tendencies and defending an inclusive appreciation for the unique individuality of all learners in contexts of diverse communities.

Secondly, we suggest that inclusive educators must take the inevitable ambivalence of communities seriously especially regarding their own theories and practices. Bauman (2000) [13] (p. 172) concisely observes: "An 'inclusive community' would be a contradiction in terms." This statement points to the necessity of understanding community in the context of inclusive education in a non-essentialist way. Inclusive educators must understand that the communities they themselves build are always a cultural construction that must be kept open for further deconstruction and reconstruction in order to include more diversity and do justice to the democratic claims of participation of all who want to join them. The idea of inclusion must always transcend one's own 
community in the sense that inclusion means the openness to interact with others and strangers across borders. Part of the ambivalence of communities, in this connection, is that all communities, as cultural and discursive constructions, tend to develop their own language games, vocabularies, and forms of representation and to limit other ways of articulation. In so far as they do so, they risk neglecting diversity and the appreciation of unique individualities, experiences, and backgrounds beyond their own self-conception as a community. In Germany, for example, we observe a strong tendency-not only in public debate, but also among academics, educational policy makers, and teachers-to reduce the idea of inclusion to the integration of students with disabilities into the regular school system (as an example see: Klemm (2015) [20]). This tendency is understandable against the background of the tradition of exclusion that is deeply embedded in the history of the German tripartite school system from the 19th century on. However, it widely blocks conceiving of inclusion in the more general sense as stated, for example, in the Toronto District School Board (2011) [21]. We believe that one can only understand the deep and necessary connections of inclusion with democracy and education in a full sense when one fully comprehends that inclusion is a program of antidiscrimination on all levels in society and education. This includes the insight that the five standards of inclusion mentioned above are themselves constructions developed out of the social and political claims raised by contingent social movements in the second half of the 20th century. These standards are relevant until today, but they are also open for the construction, deconstruction, and reconstruction of further democratic claims. They themselves represent language games in the context of discursive formations. They must keep a reflective and self-critical sense of ambivalence regarding the awareness that no language game can ever be all-inclusive (see Rorty (1989) [22]).

(3) Technologies of power influence "the conduct of individuals and submit them to certain ends or domination, an objectivizing of the subject" (Foucault (1988) [14] (p. 18)). Such technologies can be found in any society because they are necessary for the coordination of functions and roles, the assignment of social status, the divisions of labor, judicial relations, etc. They often build on hierarchies and rankings. We find them in the forms of political organization as well as in institutions like the family, the school, the military, the court, the prison, the hospital, the workplace, and the state. They constitute apparently objective and stable constellations for the positioning of subjects in relation to each other. In this connection, Foucault also speaks of dispositifs of power as a name for complex cultural constellations of practices, discourses, and institutions in which subjects interact. He especially focuses on the productive aspects of power in the sense that dispositifs generate formations of knowledge and discourses, positions of subjectivity, constellations of institutions, systems of interaction, and networks of practice. It is characteristic of his understanding of modern power relations that all individuals who are included in such contexts partake in the enactment and reinforcement of the prevailing power relations through their roles and behaviors.

"For example, you look at a dispositif in the Foucauldian sense when you consider how in a given time and society, say ours, operations of measurement in education form a constellation of practices, ways of talking and using specific ideas or concepts, methods of research, terms of theoretical reflection, reconstruction of institutions, framing of horizons, mainstreaming of opinions with consequences for the life of many. From Foucault's pragmatic perspective, we can recognize such dispositifs from the effects they produce ... Th[is] dispositif of measurement is highly productive. It produces not only such worldwide recognized programs like PISA, but, at the same time, the very effects and changes, e.g., in the attitudes and expectations of teachers and students, the general public, scientific communities, governments, and educational bureaucracies. Even on a global scale, measurement in education appears as a dispositif with mighty power effects if we think of poor societies and cultures that need development in all areas of life, including cultural and political contexts in great diversity, but are driven by the dominant will to measurement to reduce their educational perspectives to the production of 'human capitals.'" (Garrison/Neubert/Reich (2016) [2] (p. 142)) 
Regarding questions of inclusive education, some important aspects in this connection concern the internal and external power relations that constitute a community of learners. Here, Dewey's two criteria of the democratic quality of a given group, community, or society-stated in the seventh chapter of "Democracy and Education" - give us a start for critical reflection on the ambivalences of communities in contexts of power.

Dewey's internal criterion asks: "How numerous and varied are the interests which are consciously shared" in the group or community? (MW 9: 89) With Foucault, we must concede that we can never evade power relations altogether. Rather, power must be seen in its network-like qualities as something that pervades all individuals in a given context. The important question, though, is how we can counteract one-sided forms of power asymmetries in inclusive settings. The question points to the relation between leadership and participation in such communities. It is about the construction and negotiation of educational roles. Research shows (see Messner and Reusser (2000) [23]) that in many cases early socialization of future teachers (i.e., student teachers) constitutes and even determines to a large degree their attitudes and beliefs regarding educational roles and the attendant power relations. For inclusive communities, based on principles of diversity and participation, it is all the more essential that they develop a constructive and critical culture of communication which enables all participants to address relations of power and to participate in the negotiation of reciprocal roles within the community. Especially important is the avoidance of fixed hierarchies that deny the possibility of critique. There is a positive aspect in the role of leadership that should not be depreciated in the context of inclusive communities. Leadership in the sense of support, assistance, guidance, counseling, and facilitating of processes of communication, negotiation, and decision-making has a genuine role in inclusive education. Many examples (see: Booth and Ainscow (2011) [10]; Lütje-Klose et al. (2016) [24] (p. 113)) show that educational leaders, like principals, teachers, and also students who have become experts in areas of interest, play an important role in the successful organization and implementation of good practices of learning for all. Yet, the ambivalence of community appears in this context as an inextricable ambivalence of leadership. There must be a clear understanding in inclusive contexts that agency cannot be reduced to a single and unambitious leadership. All partakers in a community must have sufficient chances of being agents who pursue their individual and social interests and intentions, participants who perform their social roles and responsibilities in unique ways, and observers who reflect, interpreter, discuss, negotiate, and criticize the interaction in the community. Democracy relies on the ability of self-governance. With Dewey we insist that this idea of self-governance applies to educational communities. Therefore leadership must always be balanced with claims to self-governance on the part of all. This is a fundamental principle of inclusion.

Dewey's external criterion wonders: "How full and free is the interplay with other forms of association?" (MW 9: 89). In accordance with inclusive principles, broadly understood (see: UNESCO (2005) [25] (p. 12); Reich (2014) [12]), we must never conceive of communities in isolation. Their external relationships are as important as their internal ones. The ambivalences of communities in contexts of power concern not only internal relations, but equally the broader contexts of society and culture in which such communities operate. In our time, even more than in Dewey's, most local communities are embedded in many complex ways in global interrelations. Therefore, one inclusive slogan must be: "Learn locally, think globally!" If we consider these aspects from a Foucauldian view, we must recognize that communities are always part of the larger dispositifs in societies including complex power relations. Inclusion cannot be won against society. It is first of all a social and political task and function, grounded in human rights. It stands against discrimination and undemocratic practices on all levels of society. Inclusive educators therefore must never conceive of their own community or school as an "island of bliss," on which they perform their own isolated Robinsonade. Equally, we think a danger that should not be underestimated is that inclusion partly becomes a theoretical debate of the relatively privileged or confined to academic communities and universities with not enough connections to other practices, discourses, and institutions in society. In order to make inclusion in a broader sense successful in education as well as in society as a whole, educational communities, 
like schools, must take pains to establish as many and complex relations as possible to all relevant social and cultural contexts. An inclusive school must be an open school that entertains a wide, diverse, and continual interplay with the local neighborhood, families, social services, cultural workers, institutions of civil society, representatives of business and vocational life, agents in media, politics, and administration as well as many other partners on a local, regional, and global levels including international cooperation. In the best sense, the school itself becomes a mediator and multiplier for the intercommunication between these often relatively isolated areas or compartments of social life. This fully accords with Dewey's understanding of the relation of The School and Society (MW1: 1-111). Democratic society needs inclusive education and schooling in order to become more inclusive itself regarding its diverse forms of discrimination and marginalization. With Foucault we can understand why the intercommunication is often difficult, long-lasting, and tedious: There are powerful dispositifs as, for instance, the case of Germany's established exclusionary handling of disabilities in society (the often deplored lack of accessibility in the public transportation system may serve as an example, here) and the deeply embedded practices of selection in the school system. Through the traditionally very selective perception and treatment of children with different talents and their confinement in predetermined and narrow institutional channels (like the Hauptschule, Realschule, Gymnasium, Förderschulen of many kinds), habits, attitudes, beliefs, perceptions, and preferences have been formed that reinforce the dispositif of selection and exclusion - as we choose to call it here-including its complex power effects.

(4) Technologies of the self "permit individuals to effect by their own means or with the help of others a certain number of operations on their own bodies and souls, thoughts, conduct, and way of being, so as to transform themselves in order to attain a certain state of happiness, purity, wisdom, perfection, or immortality." (Foucault (1988) [14] (p. 18)) Foucault uses the term "technologies" in this connection to emphasize that for him the self is not a somehow essential and given core of personal identity but socially constructed through cultural practices that are deeply imbued by effects of the other forms of technologies. Technologies of the self are necessary to create, develop, and sustain practices through which individuals can deploy and release their constructive and creative potentials to position themselves in the contexts of social life and living together with others. If they are successful, Foucault speaks of "arts of living". They are instruments for self-transformation that individuals create and employ together with other individuals and communities. In a Deweyan sense, they constitute the necessary means of educational growth on individual as well social levels.

Regarding the ambivalences of community and the attendant challenges for inclusive education today, we think that the technologies of the self play an important part. Educational communities constituted under democratic and inclusive principles must offer spaces for the development and cultivation of authentic and reliable relationships, because relationships of care for oneself and others are necessary for an effective generation, implementation, and realization of the technologies of the self. The inclusive approach insists that these opportunities and ways of support should be given to all learners. With Bauman, though, we have seen that in the face of the "new fragility of human bonds" the status of communities has itself changed from solid to liquid modernity. Communities increasingly appear as constructed rather than given, achievements rather than taken for granted conditions, projects rather than pre-established components of life worlds. This implies that communities in our time are often more precarious than stable, fluid rather than fixed, and continuously have to be nurtured lest they vanish into the void. Here we find another core ambivalence of communities in our time with important implications for inclusive education. It concerns the sustainability of communities and the work that has to be invested to keep them alive. Relative sustainability of educational communities is indispensable because the level of relationships is so fundamental for inclusive education, especially under the viewpoint of the technologies of the self. However, individuals in liquid modernity have learnt for good or bad that the establishment of bonds and relationships is embedded in kaleidoscopic life projects they themselves have to work on continuously. They need relationships, but they also have to balance involvements in communities with their own claims to individual liberties. An all too stable and comprehensive community would easily appear to most of them as a kind of prison and offense to their legitimate claims as individuals. An all too radical loss of relationships, community bonds, 
and ways of belonging, on the other hand, easily brings up fears of identity diffusion and deprivation of orientation. We have seen above with Bauman that this ambivalence accounts for the unavoidable paradoxes of communitarianism in our time. Here we conclude that inclusive education must respond to the ambivalence with a reinforced emphasis on the importance of reliable and authentic relationships in education on all levels in theory and practice. Only individuals that have sufficient opportunities to develop their technologies of the self in caring relationships with others will be able to participate effectively and autonomously in other communities and contexts in their professional as well as personal lives. They may even have achieved the necessary capacities to create new relationships and communities with others when needed.

\section{Education as Growth for All-the Role of Communities in Inclusive Education}

In the fourth chapter of Democracy and Education, Dewey observes: "Since growth is the characteristic of life, education is all one with growing; it has no end beyond itself. The criterion of the value of school education is the extent in which it creates a desire for continued growth and supplies means for making the desire effective in fact." (MW 9: 58) We have argued throughout this essay that the Deweyan approach of Democracy and Education is still relevant today and at the same time needs to be reconstructed in view of ongoing challenges and conditions of contemporary life. Dewey insists that educational growth can be best obtained under democratic conditions. For him, the growth of individuals is always connected with social growth that includes diverse contexts of living together in society. He observes "that the relation between democracy and education is a reciprocal one, a mutual one, and vitally so." (LW 13: 294) He further claims that: "Since education is the keystone of democracy, education should be truly democratic." (LW 9: 393) Our essay has suggested that, in the contexts of today, this claim implies that democracy and education must include debates on inclusion in the broad and generous sense that has been established in the last two decades on an international scale through programs and policies like the Toronto District School Board. Our special focus has been on the necessity and ambivalences of communities in this connection. With Dewey, we have seen that educational growth is impossible without communities. The challenge that we see for inclusive education today consists in considering and responding to the many and complex ambivalences of communities in liquid modernity which we have depicted and discussed with Bauman. With Foucault, we have distinguished four indispensable levels of reflection that inclusive education must take seriously if it is not to become naïve and superficial regarding such complex social interrelations. Dewey writes: "Power to grow depends upon need for others and plasticity." (MW 9: 57) It is today best realized in educational communities that are diverse and participatory and provide flexible and reflective responses to the complex, ambivalent, and often contradictory life conditions in liquid modernity.

Author Contributions: The essay has been jointly written by both authors.

Conflicts of Interest: The authors declare no conflict of interest.

\section{Abbreviations}

Citations of the works of John Dewey are from the critical edition, The Collected Works of John Dewey, 1882-1953, published by Southern Illinois University Press, Carbondale and Edwardsville. Volume and page numbers follow the initials of the series, e.g., MW 9: 1.

Abbreviations for the volumes used are:

MW 1-15 = The Middle Works (1899-1924), Vol. 1-15;

LW 1-17 = The Later Works (1925-1953), Vol. 1-17.

\section{References}

1. Garrison, J.; Neubert, S.; Reich, K. John Dewey's Philosophy of Education. An Introduction and Recontextualization for Our Times; Palgrave Macmillan: New York, NY, USA, 2012.

2. Garrison, J.; Neubert, S.; Reich, K. Democracy and Education Reconsidered-Dewey after One Hundred Years; Routledge: New York, NY, USA, 2016. 
3. Dewey, J. The Collected Works of John Dewey; Southern Illinois University Press: Carbondale, IL, USA; Edwardsville, IL, USA, 1882-1953.

4. United Nations Educational; Scientific and Cultural Organization (UNESCO). Guidelines for Inclusion. Ensuring Access to Education for All. Available online: http://unesdoc.unesco.org/images/0014/001402/ 140224e.pdf (accessed on 14 December 2016).

5. Westbrook, R.B. John Dewey and American Democracy; Cornell University Press: Ithaca, Greece; London, UK, 1991.

6. Eldridge, M. Dewey on Race and Social Change. In Pragmatism and the Problem of Race; Lawson, B.E., Koch, D.F., Eds.; Indiana University Press: Bloomington, IN, USA, 2004; pp. 11-21.

7. Neubert, S. Democracy and Education in the 21st Century-Deweyan Pragmatism and the Question of Racism. In Studien zu Kultur und Erziehung im Pragmatismus und Konstruktivismus; Neubert, S., Ed.; Waxmann: Münster Germany, 2012; pp. 136-149.

8. Seigfried, C.H. John Dewey's Pragmatist Feminism. In Feminist Interpretations of John Dewey; Seigfried, C.H., Ed.; Pennsylvania State University Press: University Park, PA, USA, 2002; pp. 47-77.

9. Reich, K. Inklusion und Bildungsgerechtigkeit; Beltz: Weinheim, Germany; Basel, Switzerland, 2012.

10. Booth, T.; Ainscow, M. Index for Inclusion: Developing Learning and Participation in Schools; Centre for Studies on Inclusive Education (CSIE): Bristol, UK, 2011.

11. Blecker, N.S.; Boakes, N.J. Creating a Learning Environment for All Children: Are Teachers Able and Willing? Int. J. Inclusive Educ. 2010, 14, 435-447. [CrossRef]

12. Reich, K. Inklusive Didaktik; Beltz: Weinheim, Germany; Basel, Switzerland, 2014.

13. Bauman, Z. Liquid Modernity; Polity Press: Cambridge, UK, 2000.

14. Foucault, M. Technologies of the Self. In Technologies of the Self; Martin, L.H., Goodman, H., Hutton, P.H., Eds.; University of Massachusetts Press: Amherst, MA, USA, 1988; pp. 16-49.

15. World Health Organization. World Report on Disability. Available online: http://www.who.int/disabilities/ world_report/2011/en/ (accessed on 17 June 2015).

16. Peters, M.A.; Besley, T.A.C. Social Exclusion/Inclusion: Foucault's analytics of exclusion, the political ecology of social inclusion and the legitimation of inclusive education. Open Rev. Educ. Res. 2014, 1, 99-115. [CrossRef]

17. Stiglitz, J.E. The Great Divide; Allen Lane \& Penguin: London, UK, 2015.

18. Hall, S. The West and the Rest-Discourse and Power. In Formations of Modernity; Hall, S., Gieben, B., Eds.; Polity Press: Cambridge, Oxford, UK, 1992; pp. 275-331.

19. Reich, K. Die Ordnung der Blicke. Vol. 1: Beobachtung und die Unschärfen der Erkenntnis. Vol. 2: Beziehungen und Lebenswelt. 2009 a, b. Available online: http://konstruktivismus.uni-koeln.de/reich_ works/buecher/ordnung/index.html (accessed on 22 August 2016).

20. Klemm, K. Inklusion in Deutschland. Daten und Fakten; Bertelsmann: Gütersloh, Gütersloh, 2015.

21. Toronto District School Board. Equity Foundation Statement. Available online: http://www.tdsb.on.ca/ wwwdocuments/programs/Equity_in_Education/docs/Equity_Foundation_Statement.pdf (accessed on 17 June 2015).

22. Rorty, R. Contingency, Irony, and Solidarity; Cambridge University Press: Cambridge, UK; New York, NY, USA; Melbourne, Australia, 1989.

23. Messner, H.; Reusser, K. Die berufliche Entwicklung von Lehrpersonen als lebenslanger Prozess. Beiträge zur Lehrerbildung 2000, 18, 157-171.

24. Lütje-Klose, B.; Serke, B.; Hunger, S.K.; Wild, E. Gestaltung kooperativer Prozesse und Schulstrukturen als Merkmal effektiver Unterrichtung von Schülerinnen und Schülern mit sonderpädagogischem Förderbedarf im Lernen. Ergebnisse von Schulleitungsinterviews aus der BiLief-Studie. In Kooperation im Kontext schulischer Heterogenität; Kreis, A., Wick, J., Kosorok Labhart, C., Eds.; Waxmann: Münster, Germany, 2016; pp. 109-126.

25. United Nations. Convention on the Rights of Persons with Disabilities. Available online: http://www.un. org/disabilities/convention/conventionfull.shtml (accessed on 22 June 2015).

(C) 2017 by the authors; licensee MDPI, Basel, Switzerland. This article is an open access article distributed under the terms and conditions of the Creative Commons Attribution (CC-BY) license (http:/ / creativecommons.org/licenses/by/4.0/). 